\title{
Arduino Based Automatic License Issuing System
}

\author{
D.Vijendra Babu, S.Dhanushya, S.Aravind, V.P.Mohammed Aslam
}

\begin{abstract}
To prevent fatal deaths and injuries to Human, issuing of driving license to be automated and streamlined. The purpose of the paper is to propose a prototype to assist the automated license issuing system in a foolproof manner. Arduino based controller is utilized along with various sensors along with transmission of vehicle data through Zigbee controller. The results displayed will be helpful in examining the driving pattern of person undergoing test procedures by the Government authorities. Personal details of the driving person is been displayed along with driving pattern and license is issued only if they undergo the test by preventing any other false procedures.
\end{abstract}

Index Terms: driving pattern, license, Zigbee, Arduino, sensors

\section{INTRODUCTION}

B ased on 2017 Survey on Road accidents in India, 59\% of License holders never undergone any test and few understand the rules. The loopholes in system makes people to skip the rules/procedures and flout the law. leads to Vehicles possessed by untrained persons is equivalent to a weapon and they are a great threat to the road safety. $10.4 \%$ of the persons without license and $79.9 \%$ of persons of valid license holders are the reasons for road accidents. The survey highlights the need of mandatory driving test due to which majority of them drive without knowing the essential rules. An automated license issuing system with monitoring the driving pattern of the intended person becomes the need of the hour and these data's to be analyzed and compared for various purposes.

\section{LITERATURE SURVEY}

R.Danieliene, 2008 discusses about comparing the existing systems effectively. B.Wallace,et all,2014 discuses about analysis techniques to discriminate among various drivers of a vehicle on the parameter such as velocity, route option, slot of a day and acceleration.S.Yadav,et all,2016 discusses about monitoring the drivers performance with various parameters such as load, speed and acceleration using Controller Area Network. The prototype also analyses the data's, identifies errors and indicates the rectification measures. B.Jayalakshmi,et all, 2017 describes about a

Revised Manuscript Received on September 22, 2019.

Dr.D.Vijendra Babu,ECE Department, Aarupadai Veedu Institute of Technology, Vinayaka Mission's Research Foundation, Deemed to be Univesity,Chennai,India. Email:vijendrababu@ avit.ac.in

S.Dhanushya, S.Aravind,V.P.Mohammed Aslam,UG Students,ECE Department, Aarupadai Veedu Institute of Technology, Vinayaka Mission's Research Foundation, Deemed to be Univesrity,Chennai, India. proposal of automation of driving test by utilizing PIC controller and thus aids in decrease of fatal deaths due to accidents. It analyses about the driving skill effectively.

\section{SYSTEM DESIGN}

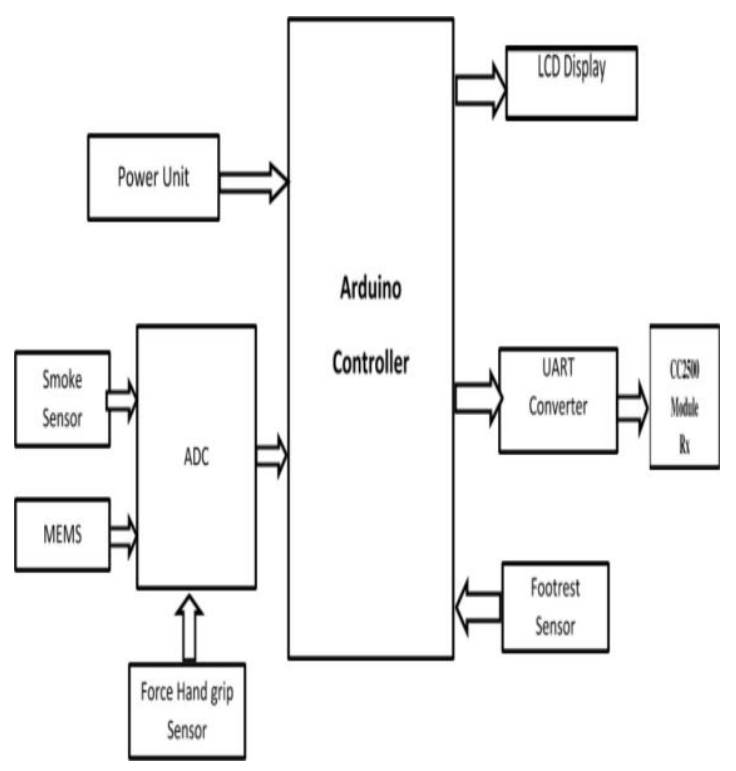

Fig. 1.Transmitter Block Diagram

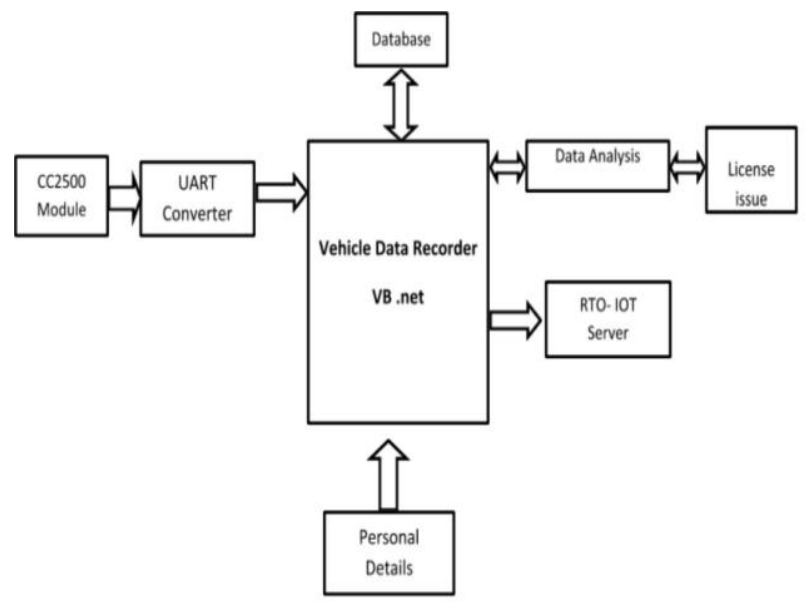

Fig. 2.Receiver Block Diiagram

Fig. 1 displays the Transmitter block diagram \& Fig.2 displays the Receiver block diagram.The Transmitter unit is also called as Vehicle unit and Receiver is called as Vehicle data recorder.Force sensoe,Acceleration sensor,Footrest sensor and Gas sensor are placed in the prototype. 
Force sensor is utilized for detection of force during acceleration during license test.Acceleration sensor consists of two values $\mathrm{x}$ and $\mathrm{y}$ to measure the movement of handle bar.Gas sensor is used to detect the emission gas based on ppm.Footrest sensor is to determine the ststus of the drivers footrest placemnt in vehicle continuosly in digital format.

\section{HARDWARE MODULE}

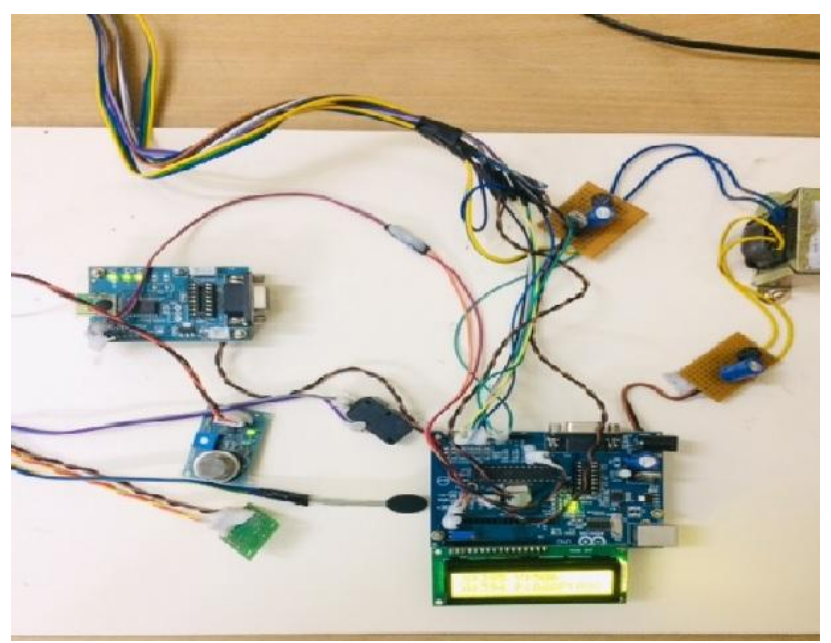

Fig. 3.Transmitter Unit

Fig. 3 displays the snapshot of Transmitter Unit.X \& Y describes the Motion sensor variation.G describes the Gas sensor variation.P describes the Footrest sensor gear change.F describes acceleration .

\section{RESULT AND DISCUSSION}

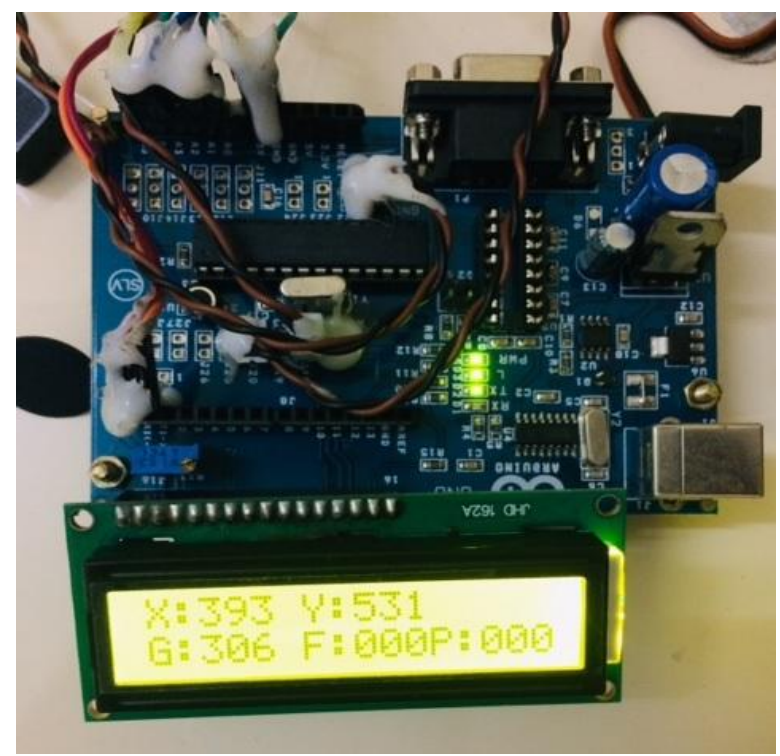

Fig. 4.Transmitter LCD Display

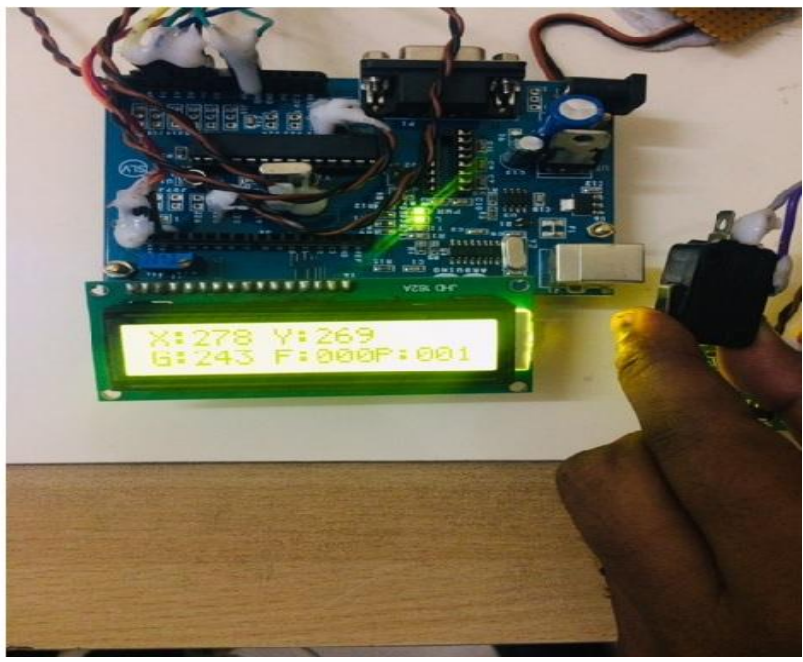

Fig. 5.Footrest sensor gear change

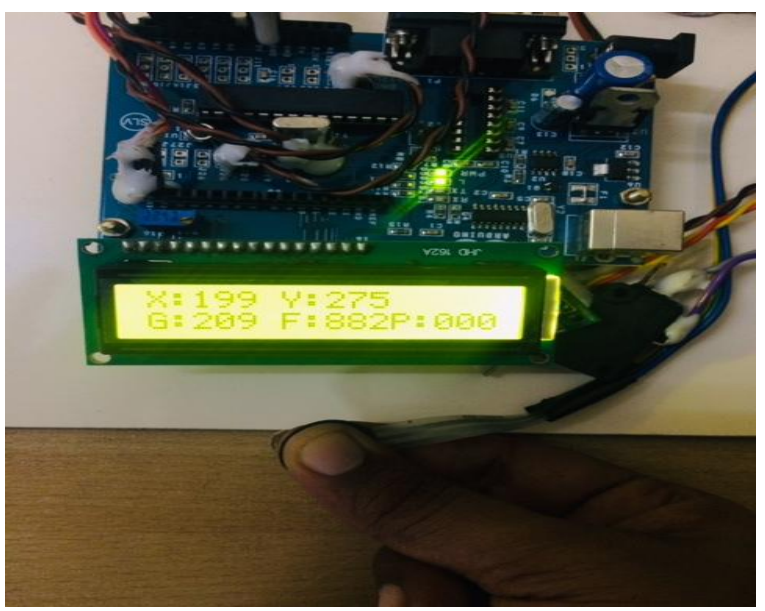

Fig. 6.Acceleration sensor

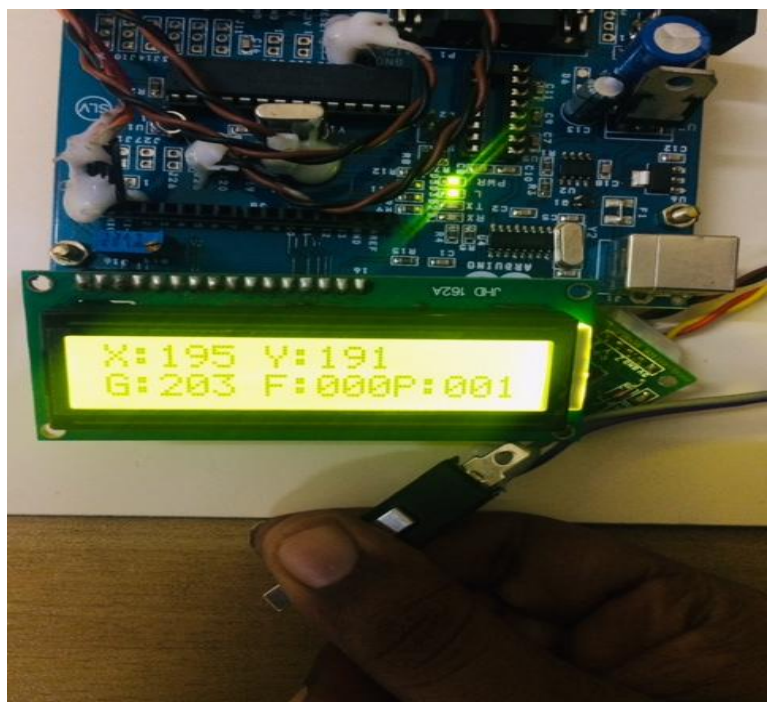

Fig. 7.Gas sensor variation

Published By:

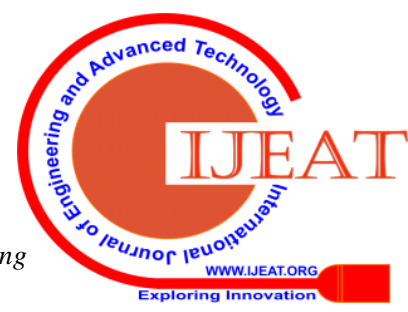




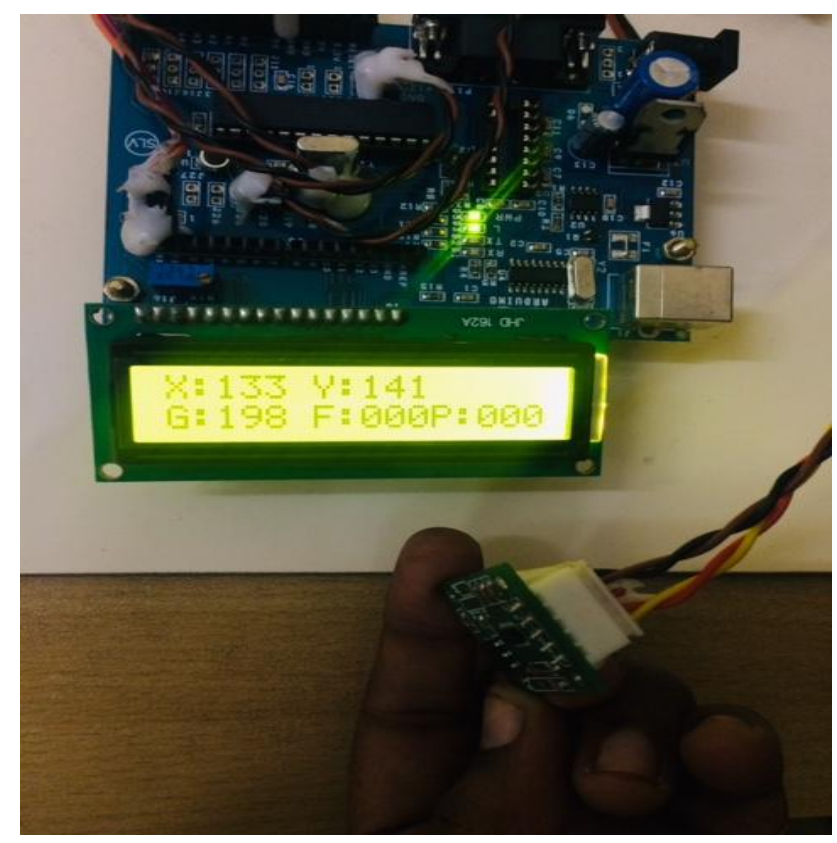

Fig. 8.Motion sensor variation

Fig.4 displays the Transmitter LCD display.Fig.5 displays the Footrest sensor gear change.Fig.6 displays Acceleration sensor.Fig.7 displays Gas sensor variation. Fig. 8 displays Motion sensor variation.

\section{CONCLUSION}

In the demonstration of the prototype, the results provide an insight about the driving pattern tested during license process with the aid of various sensor outputs. The license can be issued based on the performance and these details are stored for future reference and the system becomes foolproof as aimed.

\section{REFERENCES}

1. 1.Soon-il Jeon, et all, "Multimode driving control of a parallel hybrid electric vehicle using driving pattern recognition", Journal of Dynamic Systems, Measurement and Control, 2002, 124(1), pp.141-149.

2. 2.A.Abdelsalam,S.Cui, "A Fuzzy logic global power management strategy for hybrid electric vehicles based on a permanent magnet electric variable transmission", Energies 2012, 5, 1175-1198.

3. 3.R.Danieliene and E. Telesius, "Analysis of computer-based testing systems," 2008 Conference on Human System Interactions, Krakow, 2008, pp. 954-958

4. 4.B.Wallace, R. Goubran, F. Knoefel, S. Marshall and M. Porter, "Measuring variation in driving habits between drivers," 2014 IEEE International Symposium on Medical Measurements and Applications, Lisboa, 2014, pp. 1-6.

5. 5.S. Yadav, A. Pohekar and K. Surender, "Performance Monitoring System for driver with light motor vehicle (LMV) learner's license," 2016 International Conference on Computing Communication Control and automation (ICCUBEA), Pune, 2016, pp. 1-6.

6. 6.B.Jayalakshmi, A. Vijayan and V. Gopikrishnan, "Driving license test automation," 2017 International Conference on Intelligent Computing, Instrumentation and Control Technologies, Kannur, 2017, pp. 748-751.

\section{Authors ProfiLe}

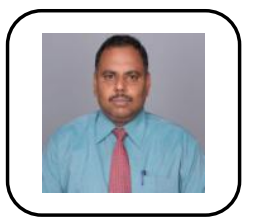

Dr.D.Vijendra Babu earned his Ph.D. from Jawaharlal Nehru Technological University, Hyderabad, M.Tech. from SASTRA Deemed to be University \& B.E. from University of Madras. He is currently designated as Vice Principal \& Professor. He has 2 Decade of Experience in the field of Education, Research \& Administration at various levels. He has served as HoD for 13 Years \& delivered numerous Invited Lectures in the area of $5 \mathrm{G}$ Communication, Artificial Intelligence, Robotics \& Image/Video Processing at various Institutions. He has chaired several Sessions on International/National Conferences. He has published $80+$ papers in International Journals/Conferences. He is a recipient of Best Paper Award in IEEE International Conference \& Active ISF Award. $\mathrm{He}$ is Secretary of IEEE Robotics \& Automation Society. He is Senior Member of IEEE, Fellow of IETE, Life member in ISTE, BES (I), ACEEE \& IACSIT. 